\title{
Ultrahigh-Energy-Density Sorption Thermal Battery Enabled by Graphene Aerogel-Based Composite Sorbents for Thermal Energy Harvesting from Air
}

\author{
Taisen Yan, ${ }^{\nabla}$ Tingxian $\mathrm{Li}^{*},{ }^{\nabla}$ Jiaxing Xu, Jingwei Chao, Ruzhu Wang, ${ }^{*}$ Yuri I. Aristov, \\ Larisa G. Gordeeva, Pradip Dutta, and S. Srinivasa Murthy
}

Read Online

ABSTRACT: Sorption-based thermal storage has drawn considerable attention for sustainable and cost-effective thermal management and energy storage. However, the low sorption capacity of sorbents is a long-standing challenge for achieving high-energy-density sorption-based thermal storage. Herein, we demonstrate an ultrahigh-energy/power-density sorption thermal battery (STB) enabled by graphene aerogel (GA)-based composite sorbents for efficient thermal harvesting and storage with record performance. Scalable GA-based composite sorbents with high salt loading are synthesized by confined calcium chloride inside a GA matrix $\left(\mathrm{CaCl}_{2} @ \mathrm{GA}\right)$, showing fast sorption kinetics and a large sorption capacity up to $2.89 \mathrm{~g} \cdot \mathrm{g}^{-1}$ contributed by the GA matrix and chemisorption-deliquescence-absorption of $\mathrm{CaCl}_{2}$. The

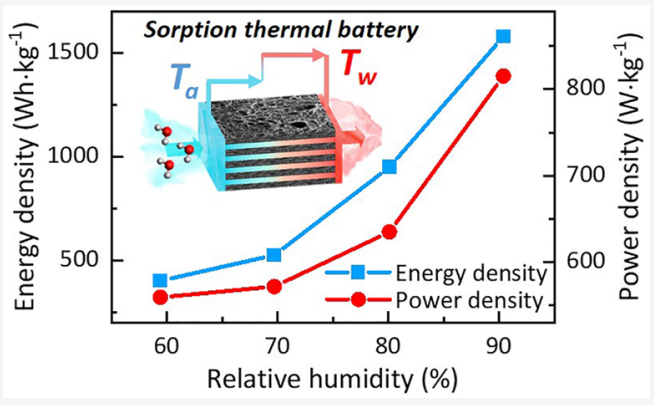
STB realizes thermal charging-discharging via the multistep water desorption-sorption of $\mathrm{CaCl}_{2} @ \mathrm{GA}$ sorbent with the humidity from air. Importantly, the lab-scale STB exhibits record energy density of $1580 \mathrm{Wh} \cdot \mathrm{kg}^{-1}$ and power density of $815 \mathrm{~W} \cdot \mathrm{kg}^{-1}$ for space heating. Our work offers a promising low-carbon

sorption working pairs, sorbent-water pairs have attracted extensive attention for sorption-based energy devices because of the distinct advantages of nontoxicity, eco-friendliness, lowcost, and the high phase change enthalpy of water. ${ }^{3}$ Moreover, moisture in the air is an abundant source of water and is available everywhere; ${ }^{10}$ thus, sorption-based thermal energy harvesting from humidity is an appealing way to provide thermal energy by capturing moisture from ambient air. ${ }^{11}$

However, water sorbent materials commonly suffer from low water capacity, weak mass transport, and poor thermal conductivity. ${ }^{2,10}$ For traditional porous physisorption materials such as silica gels and zeolites, ${ }^{3,12}$ their low water sorption capacities $\left(<0.4 \mathrm{~g}_{\text {water }} \cdot \mathrm{g}_{\text {sorbent }}{ }^{-1}\right)$ make them unsuitable for highenergy-density sorption-based thermal energy storage. The

Received: February 8, 2021

Accepted: April 8, 2021

Published: April 14, 2021
Cite This: ACS Energy Lett. 2021, 6, 1795-1802 route for efficient thermal energy harvesting, storage, and utilization.

\section{$\mathrm{T}$} hermal energy has widespread applications in comparison to other forms of energy because more than $90 \%$ of the world's primary energy is consumed or wasted in the form of heat. ${ }^{1}$ Therefore, exploiting advanced thermal energy harvesting, storage, and utilization are highly important to improve energy efficiency and address the inevitable problem of energy mismatch between demand and supply of renewable energy. Sorption-based thermal energy harvesting and storage is an efficient way to reallocate thermal energy for building heating, cooling, and thermal management. ${ }^{2-6}$ The sorption thermal battery (STB), ${ }^{7,8}$ in analogy with an electric battery, was proposed for high-energy-density thermal storage with energy storage density 5-10 times greater than that of sensible/latent-heat thermal storage. Thermal energy is stored in the form of the bond energy of sorbent-adsorbate working pairs during the desorption phase (thermal charging), and the stored thermal energy is released in the form of heat/cold energy during the sorption phase (thermal discharging). In particular, an STB can realize versatile and flexible energy applications of thermal energy harvesting, heat storage, and sorption cooling/sorption heating by employing advanced sorption thermodynamic cycles. ${ }^{9}$ Among different kinds of 
(a)
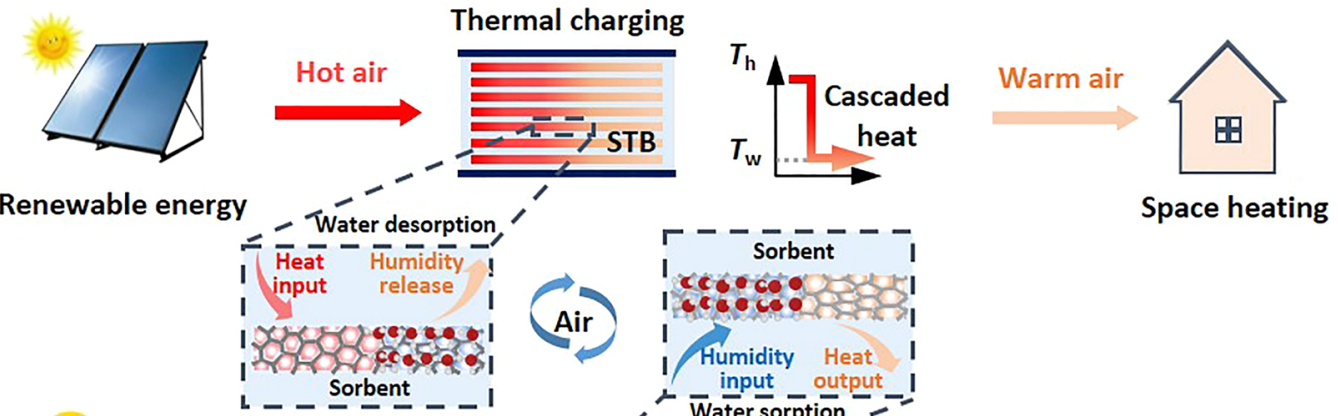

(b)
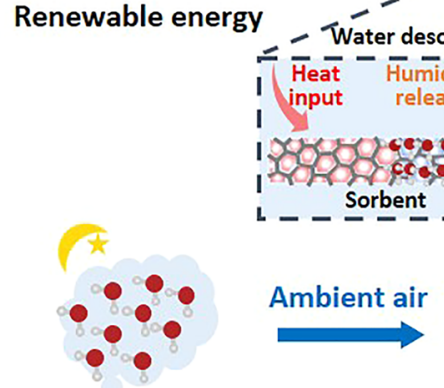

Atmospheric Humidity

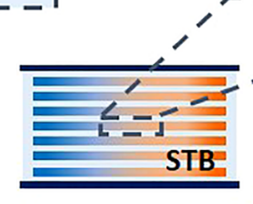

Thermal discharging
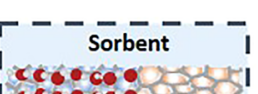

$\operatorname{coc} c 0$, th?

1

Humidity Heat I

Water sorption
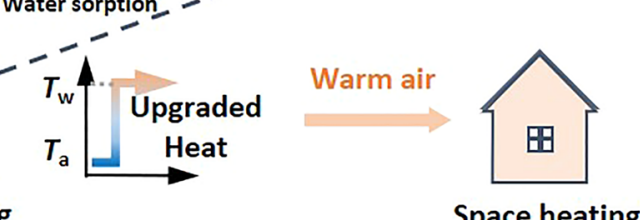

Figure 1. Working diagram of sorption thermal battery (STB) for continuous space heating. (a) Schematic of thermal energy storage and cascaded heat utilization of STB during thermal charging process, where the STB is driven by the heat input from hot air to perform water vapor desorption (left enlarged image), and the hot air becomes warm air with a temperature drop from $T_{h}$ to $T_{w}$ for space heating by converting the heat energy of air into the sorption bond energy of sorbent. (b) Schematic of thermal energy harvesting and upgraded heat utilization of STB during thermal discharging process, where the STB is driven by the humidity input from ambient air to perform water vapor sorption (right enlarged image) and the ambient air is upgraded to become warm air with a temperature lift from $T_{\mathrm{a}}$ to $T_{\mathrm{w}}$ for space heating by converting the sorption bond energy of sorbent into the heat energy of air.

emerging porous materials of metal-organic frameworks (MOFs), ${ }^{4,13}$ such as MIL-101(Cr), ${ }^{14}$ MOF-801, ${ }^{15}$ MIP$200,{ }^{16} \mathrm{Ni}_{2} \mathrm{X}_{2}$ BBTA, ${ }^{17,18}$ Al-soc-MOF- $1,{ }^{19} \mathrm{MOF}-303,{ }^{20} \mathrm{KMF}-$ $1,{ }^{21}$ etc., exhibit an $\mathrm{S}$-shaped sorption isotherm with large water sorption capacity $\left(0.3-1.2 \mathrm{~g}_{\text {water }} \cdot \mathrm{g}_{\text {sorbent }}^{-1}\right)$ within a small temperature and/or pressure swing. ${ }^{22}$ However, scalable synthesis of low-cost and thermally stable MOFs is still a great challenge for water sorption-based energy devices. ${ }^{23}$ In comparison with physisorption materials, chemisorption sorbents of hygroscopic salts usually show higher water uptakes. $^{24}$ However, almost all hygroscopic salts have serious powder agglomeration and poor mass transfer during hydration-dehydration reaction processes. $^{25}$ The idea of confining salt to porous matrix (CSPM) to avoid or alleviate these drawbacks was first proposed at Boreskov Institute of Catalysis, Russia. ${ }^{26}$ In recent years, many composite "salt in porous matrix" sorbents have been reported by confining hygroscopic salts into various matrixes such as zeolite, silica gel, carbon-based porous materials, hydrogels, MOFs, etc. $^{24,27-31}$ Nevertheless, because of the low salt loading (usually $<50$ wt \%) and inadequate water sorption capacity caused by the limitation of pore volume and poor water vapor diffusion ability of the porous matrix, ${ }^{2,24}$ the resultant composite sorbents have much lower water sorption capacities when compared to the pristine hygroscopic salts. Therefore, searching for better composite sorbents is of significant importance to developing cost-effective and high-density sorption-based thermal energy harvesting and storage devices.

Herein, we report a strategy of synthesizing high-performance graphene aerogel (GA)-based composite sorbents by confining hygroscopic salts inside GA matrix (salt@GA). The resultant $\mathrm{CaCl}_{2} @ \mathrm{GA}$ composite sorbents have the capability of integrating the multistep sorption processes of chemisorptiondeliquescence-absorption of $\mathrm{CaCl}_{2}$, enabling the composite sorbents to possess large water sorption capacity and volumetric energy density up to $2.89 \mathrm{~g} \cdot \mathrm{g}^{-1}$ and $776.8 \mathrm{kWh}$. $\mathrm{m}^{-3}$, respectively. We further demonstrated a scalable ultrahigh-energy/power-density sorption thermal battery (STB) enabled by the $\mathrm{CaCl}_{2} @ \mathrm{GA}$ composite sorbent for efficient thermal energy harvesting and storage from air. The STB realizes thermal charging by converting thermal energy from hot air into sorption bond energy and achieves thermal discharging by harvesting thermal energy via capturing atmospheric humidity from ambient air. Moreover, the proposed STB achieves record high energy density of 1580 $\mathrm{Wh} \cdot \mathrm{kg}^{-1}$ and high power density of $815 \mathrm{~W} \cdot \mathrm{kg}^{-1}$ by combining cascaded heat utilization during thermal charging and upgraded heat utilization during thermal discharging. Our method offers a promising low-carbon route to synthesize high-performance composite sorbents and to realize highenergy/power-density thermal energy harvesting and storage.

The STB has thermal charging and discharging modes for space heating by harvesting thermal energy from air (Figure 1). The thermal charging-discharging modes of STB are switched by circulating air to perform the water desorption (charging state) or the water sorption (discharging state) of sorbentwater pairs. The operating performance of a sorption thermal battery (STB) depends upon the physicochemical properties of the sorbent-water pair. Specifically, the sorption transition temperature $\left(T_{\mathrm{eq}}\right)$ determines the maximum output temperature, which can be in analogy with the maximum voltage or open-circuit voltage of the electrochemical battery.

During the thermal charging phase (Figure 1a), the hot air ( $T_{\mathrm{h}}$, typically higher than $T_{\mathrm{eq}}$ ) from external heat sources (e.g., solar energy, waste heat, etc.) is pumped into the STB and drives the water desorption of sorbent-water in the STB. By converting the heat energy of hot air into the bond energy of sorbent-water by dehydration reaction, the heat-driven STB realizes thermal energy storage in the form of the bond energy of the sorbent-water pair. Simultaneously, the hot air is cooled from a temperature of $T_{\mathrm{h}}$ to $T_{\mathrm{w}}$ because of its sensible heat consumption for the water desorption of the sorbent and then becomes warm air used for space heating via a cascaded heat utilization strategy.

During the thermal discharging phase (Figure $1 \mathrm{~b}$ ), ambient air flows into the STB, and the humidity released from the 


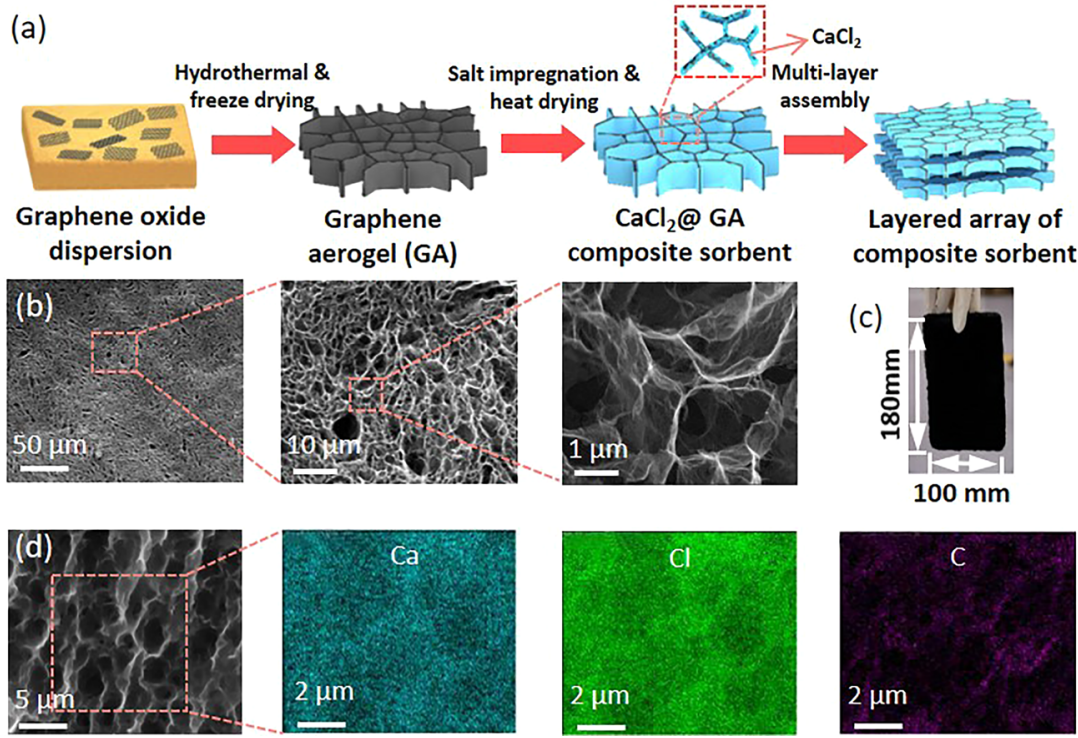

Figure 2. Synthesis and characterization of graphene aerogel-based composite sorbents. (a) Synthesis procedure of graphene aerogel (GA)based composite sorbents $\left(\mathrm{CaCl}_{2} @ \mathrm{GA}\right)$, including the hydrothermal reaction of graphene oxide (GO), the freeze-drying of graphene hydrogel (GH), the salt impregnation of graphene aerogel (GA), the heat-drying of $\mathrm{CaCl}_{2} @ \mathrm{GA}$ solution, and multilayer assembly of $\mathrm{CaCl}_{2} @$ GA sorbent sheets. (b) SEM images of 3D network graphene aerogel matrix and its enlarged SEM image showing the high porosity and homogeneous micropore structure with micrometer-level pores. (c) Optical photos of $\mathrm{CaCl}_{2} @ \mathrm{GA}$ sheet with a size of $180 \mathrm{~mm} \times 100 \mathrm{~mm} \times$ $2 \mathrm{~mm}$ used for the layered array composite sorbents in STB. (d) SEM image of $\mathrm{CaCl}_{2} @ \mathrm{GA} 30$ composite sorbent and EDS mapping of Ca, $\mathrm{Cl}$, and $\mathrm{C}$ elements.

ambient air drives the water sorption of sorbent-water in the STB. The humidity-driven STB realizes thermal energy harvesting by capturing the humidity from ambient air by hydration reaction. By converting the bond energy of sorbentwater into the thermal energy of air, the sorption heat produced by the hydration reaction of the sorbent-water pair enables the ambient air to become warm air with a temperature lift from $T_{\mathrm{a}}$ to $T_{\mathrm{w}}$. The resultant warm air is used for space heating via an upgraded heat utilization strategy. Specifically, in comparison to the intermittent heating supply and low thermal efficiency in conventional thermal storage devices, the proposed STB has the distinctive capability of realizing continuous space heating, high energy density, and superior energy efficiency by combining cascaded heat utilization during the thermal charging phase and upgraded heat utilization during the thermal discharging phase.

To promote the flexibility of STB for space heating under different air humidity conditions and to realize high-density thermal energy harvesting and storage, sorbents with excellent water sorption-desorption capacity within a wide range of relative humidity are desirable. Considering the recommended range of air temperature $\left(21-26{ }^{\circ} \mathrm{C}\right)$ and relative humidity (45-65\% RH) for space heating set by the American Society of Heating, Refrigerating and Air-Conditioning Engineers (ASHRAE), calcium chloride $\left(\mathrm{CaCl}_{2}\right)$ is chosen as one of the most promising sorbents among different hygroscopic salts owing to its appropriate equilibrium characteristics (Figure S1).

A high-performance graphene aerogel (GA)-based composite sorbent is synthesized for STB by confining calcium chloride inside a GA matrix (Figure 2). The synthesis procedure of GA-based composite sorbents mainly includes hydrothermal reaction, freeze-drying, and salt impregnation processes (Figure 2a). The graphene aerogel (GA) is first synthesized by using chemical reduction of graphene oxide
(GO) and then freeze-drying of graphene hydrogel $(\mathrm{GH})$ to serve as the porous matrix for calcium chloride ${ }^{32}$ [see details in Experimental Procedures (section S1) in the Supporting Information]. The prepared GA matrix shows high porosity and homogeneous porous structure (Figure $2 \mathrm{~b}$ ) as well as micrometer-level pore distribution (Figure S2) and plentiful oxygen-containing function groups (Figure S3).

A series of GA-based composite samples with different salt contents are prepared by confining $\mathrm{CaCl}_{2}$ into GA matrix (Table S1) using wet impregnation methods. ${ }^{33}$ To avoid the salt solution leakage of $\mathrm{CaCl}_{2} @ \mathrm{GA}$ sorbent during water uptake, its salt content can be tailored by different solution concentrations of salt according to the operating air humidity (Figure S4). The $\mathrm{CaCl}_{2} @ \mathrm{GA}$ with salt concentration of $30 \mathrm{wt}$ \%( $\mathrm{CaCl}_{2} @ \mathrm{GA}$ 30) is selected as a promising composite sorbent because of its large water uptake within a given sorption time (Table S2). The plentiful porous structure of GA matrix endows the $\mathrm{CaCl}_{2} @ \mathrm{GA}$ sorbents with extremely high salt loading up to 91-96 wt \%, much higher than the reported zeolite- (25 wt \%), ${ }^{2} \mathrm{SiO}_{2^{-}}\left(30-40\right.$ wt \%), ${ }^{34} \mathrm{MOF}-$ (70 wt $\%),{ }^{24,28,29}$ graphite- (80 wt \%), ${ }^{9}$ and hydrogel-based (85 wt $\%)^{30}$ composite sorbents.

Moreover, the size and shape of $\mathrm{CaCl}_{2} @ \mathrm{GA}$ sorbents can be easily controlled using different prefabricated molds (Figure S5), and thus, our work provides a flexible and simple method for preparing scalable GA-based composite sorbents. The $\mathrm{CaCl}_{2} @ \mathrm{GA}$ sorbents sheets with size of $180 \mathrm{~mm} \times 100 \mathrm{~mm} \times$ $2 \mathrm{~mm}$ are fabricated and selected for STB in experiments (Figure 2c). The EDS mappings show the uniform distribution of $\mathrm{Ca}^{2+}$ and $\mathrm{Cl}^{-}$inside the GA matrix, indicating that the hygroscopic salt can be evenly distributed on the pore surface of GA in the $\mathrm{CaCl}_{2} @ \mathrm{GA}$ sorbents (Figures 2d and S6).

The $\mathrm{CaCl}_{2} @ \mathrm{GA}$ composite sorbent exhibits multistep water sorption-desorption (Figure 3a), including solid-gas chemisorption from anhydrous $\mathrm{CaCl}_{2} @ \mathrm{GA}$ to $\mathrm{CaCl}_{2} \cdot 4 \mathrm{H}_{2} \mathrm{O} @ \mathrm{GA}$ at 
(a)

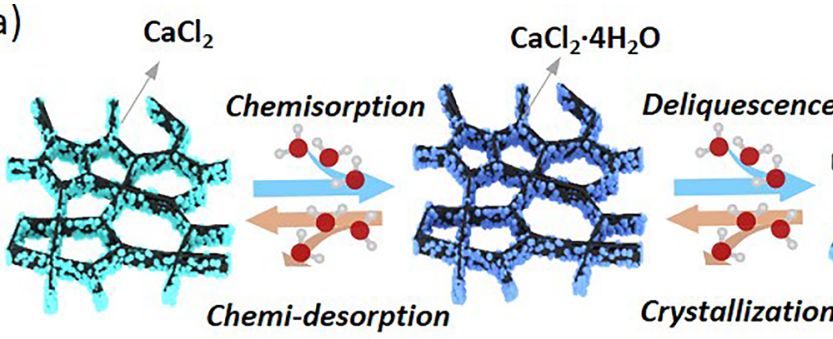

Chemi-desorption

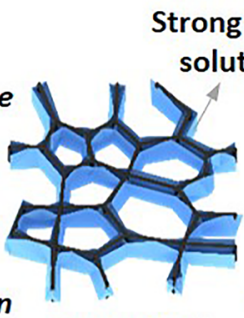

Strong $\mathrm{CaCl}_{2}$ solution@GA

(d) (b)

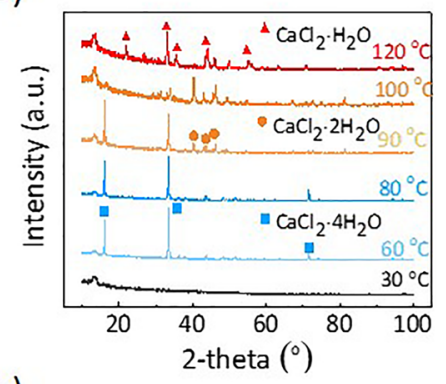

(e)

$$
\mathrm{CaCl}_{2} @ \mathrm{GA}
$$

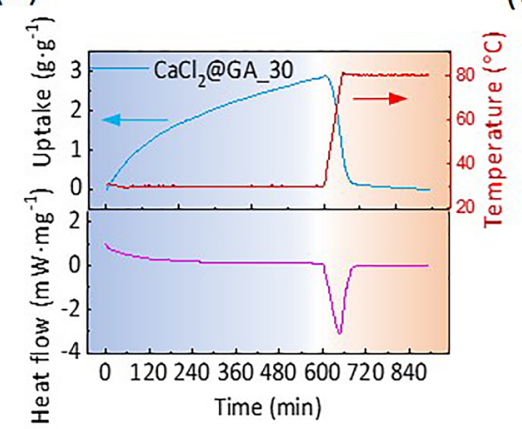

(c)

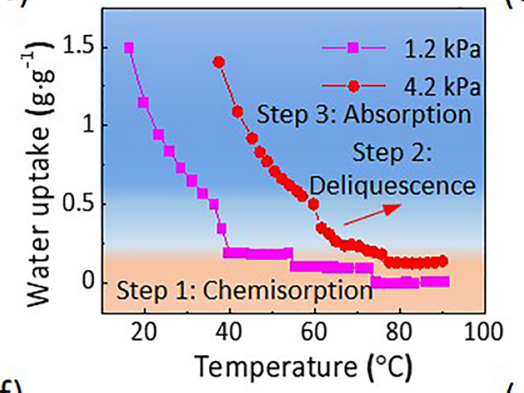

(f)

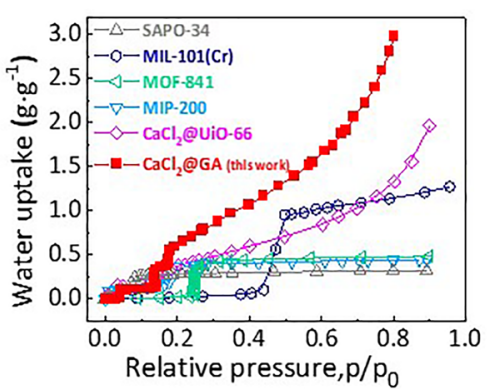

Weak $\mathrm{CaCl}_{2}$ solution

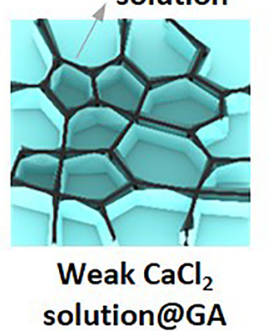

Evaporation

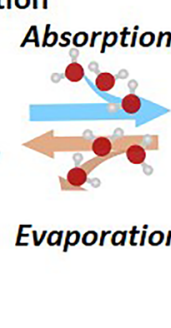

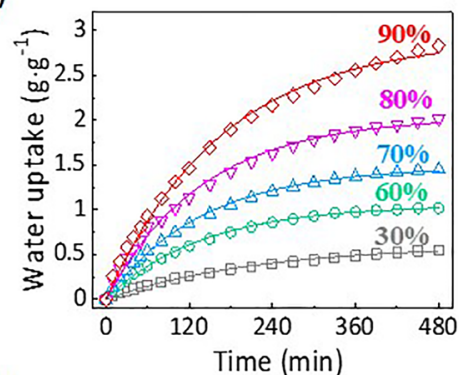

(g)

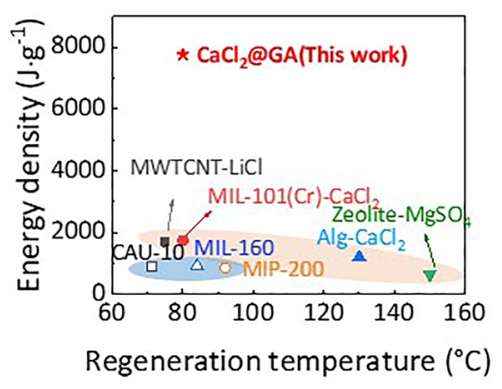

Figure 3. Multistep water sorption-desorption of $\mathrm{CaCl}_{2} @ \mathrm{GA}$ composite sorbents. (a) Schematic of multistep hydration/dehydration processes of $\mathrm{CaCl}_{2} @ \mathrm{GA}$, including solid-gas chemisorption from anhydrous $\mathrm{CaCl}_{2}$ to $\mathrm{CaCl}_{2} \cdot 4 \mathrm{H}_{2} \mathrm{O}$, solid-liquid deliquescence from CaCl${ }_{2}$. $4 \mathrm{H}_{2} \mathrm{O}$ to strong $\mathrm{CaCl}_{2}$ solution, and liquid-gas absorption from strong $\mathrm{CaCl}_{2}$ solution to weak $\mathrm{CaCl}_{2}$ solution during hydration process as well as the reverse liquid evaporation, liquid-solid crystallization, and solid chemical desorption during dehydration process. (b) XRD patterns of $\mathrm{CaCl}_{2} @ \mathrm{GA}$ sorbent at temperature ranging from 30 to $120{ }^{\circ} \mathrm{C}$ at a heating rate of $1 \mathrm{~K} \cdot \mathrm{min}^{-1}$. (c) Isobaric water sorption equilibrium of $\mathrm{CaCl}_{2} @ \mathrm{GA}$ sorbent under typical water vapor pressures of 1.2 and $4.2 \mathrm{kPa}$ at $30{ }^{\circ} \mathrm{C}$, which is measured by a self-building sorption device (Figure $\mathrm{S} 7$ ). (d) Water uptake of $\mathrm{CaCl}_{2} @ \mathrm{GA}$ sorbent at $\mathrm{RH}$ from $30 \%$ to $90 \%$ with thickness of $2.1 \mathrm{~mm}$. (e) TG-DSC curves of $\mathrm{CaCl}_{2} @ \mathrm{GA}$ sorbent under $90 \% \mathrm{RH}$ at $30{ }^{\circ} \mathrm{C}$ for sorption and $80{ }^{\circ} \mathrm{C}$ for desorption. (f) Water uptake of our $\mathrm{CaCl}_{2} @ \mathrm{GA}$ sorbent and reported typical MOFs and salt@MOF sorbents ${ }^{3,15,16,29}$ at different relative pressures. (g) Comparison of energy density between our $\mathrm{CaCl}_{2} @ \mathrm{GA}$ sorbent and the reported MOFs and salt@MOF sorbents. ${ }^{2,3,15,16,28,30,39}$ The detailed comparisons of salt loading, water uptake, and energy density are shown in Table S3.

low $\mathrm{RH}$, solid-liquid deliquesce to strong $\mathrm{CaCl}_{2}$ solution@ $\mathrm{GA}$, and liquid-gas absorption from strong $\mathrm{CaCl}_{2}$ solution@ GA to weak $\mathrm{CaCl}_{2}$ solution@GA at high $\mathrm{RH}^{35}$ The variabletemperature $\mathrm{XRD}$ patterns further confirm the multistep dehydration of $\mathrm{CaCl}_{2} @ \mathrm{GA}$ sorbent (Figure $3 \mathrm{~b}$ ). At $30{ }^{\circ} \mathrm{C}$, the $\mathrm{CaCl}_{2} @ \mathrm{GA}$ composite sorbent (in the form of $\mathrm{CaCl}_{2}$ solution@GA) shows weak diffraction peaks as the $\mathrm{CaCl}_{2}$ solution is stored inside the GA matrix. With temperature increases from 30 to $60{ }^{\circ} \mathrm{C}$, the tetrahydrate salt $\left(\mathrm{CaCl}_{2}\right.$. $4 \mathrm{H}_{2} \mathrm{O}$ ) begins to crystallize along with the water evaporation from $\mathrm{CaCl}_{2}$ solution and exists as $\mathrm{CaCl}_{2} \cdot 4 \mathrm{H}_{2} \mathrm{O} @ \mathrm{GA}$. It is necessary to note that the $\mathrm{CaCl}_{2} \cdot 6 \mathrm{H}_{2} \mathrm{O}$ crystal is not observed in the XRD patterns because the bulk hexahydrate melts at $T=$ $30.1{ }^{\circ} \mathrm{C}$, existing in its liquid state inside the GA matrix at a temperature higher than $30{ }^{\circ} \mathrm{C} .{ }^{36}$ Subsequently, within a temperature range of $90-100{ }^{\circ} \mathrm{C}$, the tetrahydrated salt $\left(\mathrm{CaCl}_{2} \cdot 4 \mathrm{H}_{2} \mathrm{O}\right)$ crystal will continue the chemical desorption to transfer to the dihyrate salt $\left(\mathrm{CaCl}_{2} \cdot 2 \mathrm{H}_{2} \mathrm{O}\right)$. The dihydrate further becomes monohydrate salt $\left(\mathrm{CaCl}_{2} \cdot \mathrm{H}_{2} \mathrm{O}\right)$ at a temperature higher than $120{ }^{\circ} \mathrm{C}$ and finally transfers to anhydrous $\mathrm{CaCl}_{2}$, leading to completely dried composite sorbent as $\mathrm{CaCl}_{2} @ \mathrm{GA}$. Compared to the pure $\mathrm{CaCl}_{2}$ (Figure S8), the $\mathrm{CaCl}_{2} @ \mathrm{GA}$ sorbent exhibits similar water sorption behaviors, confirming that the composite sorbent retains high water uptake because of its high salt loading.

The isobaric water sorption-desorption equilibrium of $\mathrm{CaCl}_{2} @ \mathrm{GA}$ composite sorbent is measured by a selfconstructed sorption device. The whole water uptake process includes multistep sorption processes: the chemisorption from $\mathrm{CaCl}_{2} \cdot \mathrm{H}_{2} \mathrm{O} @ \mathrm{GA}$ to $\mathrm{CaCl}_{2} \cdot 4 \mathrm{H}_{2} \mathrm{O} @ \mathrm{GA}$ at high temperatures (orange zone), the deliquescence of $\mathrm{CaCl}_{2} \cdot 4 \mathrm{H}_{2} \mathrm{O} @ \mathrm{GA}$ to strong $\mathrm{CaCl}_{2}$ solution@GA at $40{ }^{\circ} \mathrm{C}$, and solution absorption from strong $\mathrm{CaCl}_{2}$ solution@GA to weak $\mathrm{CaCl}_{2}$ solution@GA at low temperatures (blue zone) (Figure 3c). At high temperatures, the chemisorption makes a key contribution to water uptake, while the absorption improves water uptake at 
(a)

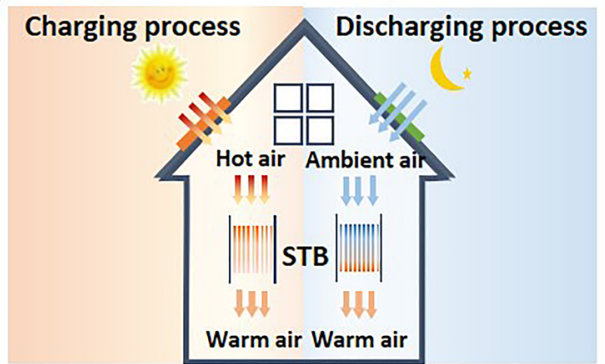

(c)

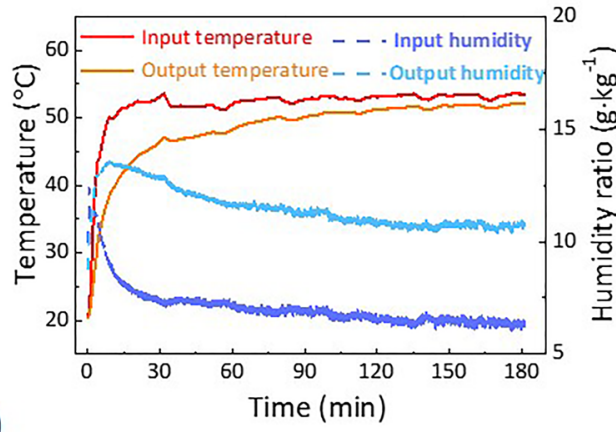

(e)

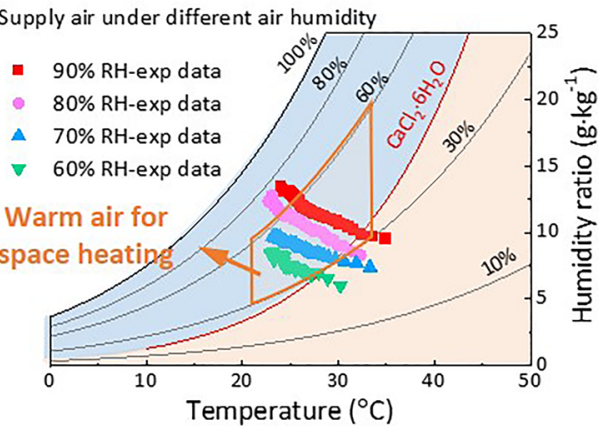

(b)

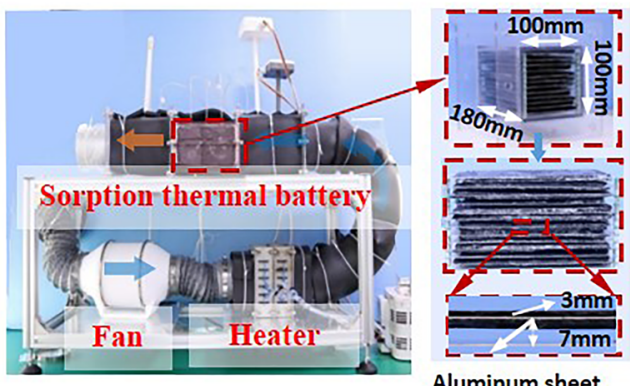

(d)

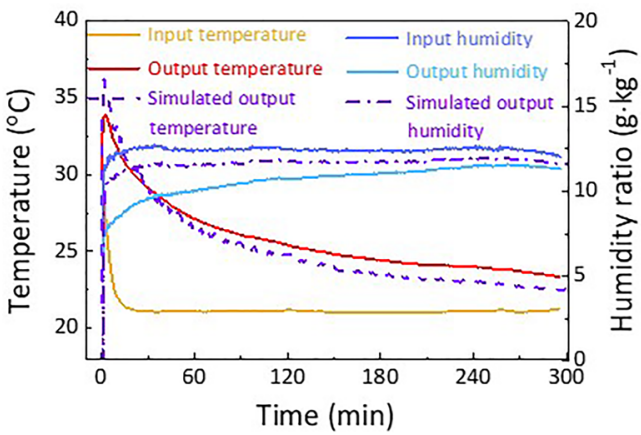

(f)

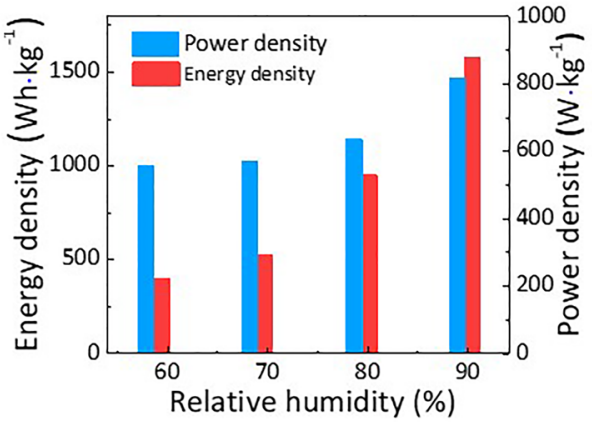

Figure 4. Working performance of $\mathrm{CaCl}_{2} @ \mathrm{GA}$-based STB for continuous space heating enabled by thermal energy harvesting and storage. (a) Schematic of charging-discharging operation modes of STB for continuous space heating of a building. (b) Optical photograph of labscale STB prototype and its packed multilayer $\mathrm{CaCl}_{2} @$ GA sheets coated on both surfaces of aluminum sheet (Figures S18 and S19). (c) Temperature and humidity evolutions of the STB for thermal energy storage and cascaded heat utilization during thermal charging process at a hot air temperature of $50{ }^{\circ} \mathrm{C}$ with flow rate of $72 \mathrm{~m}^{3} \cdot \mathrm{h}^{-1}$. (d) Temperature and humidity evolutions of the STB for thermal energy harvesting and upgraded heat utilization during thermal discharging process at air temperature of $20^{\circ} \mathrm{C}$ with flow rate of $36 \mathrm{~m}^{3} \cdot \mathrm{h}^{-1}$. The solid and dotted lines are the experimental and simulation results, respectively [see Mathematical Model for STB (section S3) in the Supporting Information]. (e) Psychrometric chart of coupled air temperature and humidity control under different input RHs for space heating. (f) Energy and power densities of $\mathrm{CaCl}_{2} @ \mathrm{GA}$-based STB at different RH conditions.

low temperatures. Moreover, chemisorption enthalpy $(55 \mathrm{~kJ}$. $\left.\mathrm{mol}^{-1}\right)$ is greater than absorption enthalpy $\left(47 \mathrm{~kJ} \cdot \mathrm{mol}^{-1}\right)$ according to the reaction enthalpy of $\mathrm{CaCl}_{2} @ \mathrm{GA}$ at different water uptakes obtained from isobaric equilibrium curves (Figures S9-S11). The $\mathrm{CaCl}_{2} @ \mathrm{GA}$ sorbent shows the flexibility of water uptake at different temperatures and water vapor pressures and thus can promote the adaptability of STB in different climatic regions compared to most reported sorbents. ${ }^{10,37,38}$

Remarkably, the $\mathrm{CaCl}_{2} @ \mathrm{GA}$ composite sorbent exhibits fast sorption rate and high water uptake with increasing air $\mathrm{RH}$ (Figure $3 \mathrm{~d}$ ). The high porosity and well-connected 3D porous structure of GA matrix enable the sorbent to achieve more than $70 \%$ of the total amount of water uptake within $3 \mathrm{~h}$ at different RH conditions. The TG-DSC results show the water sorption capacity of $\mathrm{CaCl}_{2} @ \mathrm{GA}$ is as high as $0.76-2.89 \mathrm{~g} \cdot \mathrm{g}^{-1}$ at $30-90 \% \mathrm{RH}$ (Figures 3e, S12, and S13), which is about 7-
14 times greater than the physisorption capacity of silica gels and zeolites. ${ }^{3,11}$ Moreover, the $\mathrm{CaCl}_{2} @ \mathrm{GA}$ shows excellent thermal stability without solution leakage even under a high $\mathrm{RH}$ up to $90 \%$ (Figure S14) and retains stable water uptake during repeated water sorption-desorption cycles (Figure S15). In comparison with other reported sorbents, our $\mathrm{CaCl}_{2} @$ GA sorbent exhibits greater water uptake than MOF-841, ${ }^{15}$ MIP-200, ${ }^{16} \mathrm{CaCl}_{2} @ \mathrm{UiO}-66,{ }^{28}$ and $\mathrm{CaCl}_{2} @ \mathrm{MWCNT}^{39}$ within a wide RH range (Figure 3f). Accordingly, the $\mathrm{CaCl}_{2} @ \mathrm{GA}$ sorbent has the distinct advantages of high salt loading and large energy density as high as $7768 \mathrm{~kJ} \cdot \mathrm{kg}^{-1}\left(2158 \mathrm{Wh} \cdot \mathrm{kg}^{-1}\right)$ for thermal storage applications (Figure $3 \mathrm{~g}$ and Table S3).

The proposed STB has promising applications of continuous space heating for building thermal management (Figure 4a). Thermal energy is stored by absorbing heat from hot air (e.g., solar air collector or waste heat) during thermal charging, and the stored heat is released by capturing humidity from ambient 
air during thermal discharging. To show the superiority of the proposed STB, we demonstrate a lab-scale $\mathrm{CaCl}_{2} @ \mathrm{GA}$-based STB prototype for thermal energy harvesting and storage (Figure 4b). To accelerate the desorption-sorption of $\mathrm{CaCl}_{2} @$ GA, forced air is used to improve the mass and heat transfer of $\mathrm{CaCl}_{2} @ \mathrm{GA}$ sorbent by enhancing the water vapor diffusion at the external surface of the sorbent. The layer-by-layer structures of $\mathrm{CaCl}_{2} @ \mathrm{GA}$ sorbent sheets are designed with optimized packed densities and thicknesses (Figures S16 and S17).

For a single-layer unit of STB, two $\mathrm{CaCl}_{2} @ \mathrm{GA}$ sheets with packing density of $0.33 \mathrm{~g} \cdot \mathrm{cm}^{-3}$ and thickness of $2 \mathrm{~mm}$ are coated on both surfaces of an aluminum sheet (Figure S18). A total of $24 \mathrm{CaCl}_{2} @ \mathrm{GA}$ sheets and 12 aluminum sheets are packed to assemble the layer-by-layer STB with the size of 100 $\mathrm{mm} \times 100 \mathrm{~mm} \times 180 \mathrm{~mm}$ (detailed parameters of the STB are given in Table S4). To further suppress the heat loss to ambient, the STB is enclosed by thermal insulated cotton with thickness of $20 \mathrm{~mm}$ and thermal conductivity of $0.034 \mathrm{~W} \cdot \mathrm{m}^{-1}$. $\mathrm{K}^{-1}$ (Figure S19), and the total heat loss is less than $2 \mathrm{~W}$ [see Lab-Scale Sorption Thermal Battery Device (section S4) in the Supporting Information].

During the thermal charging of STB for thermal energy storage and cascaded heat utilization (Figures 4c and S20a), hot air flows into the STB as the heat carrier to drive the sorbent to perform water vapor desorption. The thermal energy released by the hot air is stored inside the STB in the form of the sorption bond energy of $\mathrm{CaCl}_{2} @ \mathrm{GA}-\mathrm{H}_{2} \mathrm{O}$ by performing a dehydration process. Simultaneously, the hot air becomes warm air with temperature drop $\left(12{ }^{\circ} \mathrm{C}\right)$ and humidity lift $\left(5.2 \mathrm{~g} \cdot \mathrm{kg}^{-1}\right)$ due to its sensible heat consumption for water desorption, and then the warm air is used for space heating via the cascaded heat utilization strategy. The STB exhibits high charging power of $282 \mathrm{~W}$, and more than $85 \%$ of the thermal energy can be stored within $2 \mathrm{~h}$ even at a driving temperature as low as $50{ }^{\circ} \mathrm{C}$ because of the excellent mass and heat transfer. Therefore, the $\mathrm{CaCl}_{2} @ \mathrm{GA}$-based STB provides an effective route for space heating by low-grade thermal energy (such as solar heat from flat plate collector, waste heat, etc.). During the thermal discharging of the STB for thermal energy harvesting and upgraded heat utilization (Figures $4 \mathrm{~d}$ and S20b), ambient air flows into the STB as humidity carrier to drive the sorbent to perform water vapor sorption. The STB realizes thermal energy harvesting by capturing the atmospheric humidity from air with hydration reaction, and the bond energy released by $\mathrm{CaCl}_{2} @ \mathrm{GA}-\mathrm{H}_{2} \mathrm{O}$ reaction is used to heat the ambient air with temperature lift $\left(9.6{ }^{\circ} \mathrm{C}\right)$ and humidity drop $\left(4.1 \mathrm{~g} \cdot \mathrm{kg}^{-1}\right)$. The outlet warm air is suitable for space heating via upgraded heat utilization. The STB exhibits high discharging power $(153 \mathrm{~W})$ and long duration of heating supply by harvesting thermal energy from air humidity. Moreover, the STB exhibits the distinctive capacity for realizing coupled air temperature and humidity control for space heating within the recommended range of air temperature $\left(21-26{ }^{\circ} \mathrm{C}\right)$ and relative humidity $(45-65 \% \mathrm{RH})$ (Figure 4e), indicating that the STB has excellentr adaptability for space heating in different regions.

We found that high-temperature hot air is beneficial to accelerate energy storage and release warm air during both thermal charging and discharging of STB (Figure S21), while high-humidity ambient air can enable long discharging duration of heating supply $(5 \mathrm{~h})$ during the thermal discharging of STB (Figures S22 and S23). The thermal discharging of STB at different RH conditions shows that the water uptake and energy efficiency increase from 0.55 to 1.74 $\mathrm{g} \cdot \mathrm{g}^{-1}$ and from $74 \%$ to $91 \%$, respectively, when air humidity increases from $60 \% \mathrm{RH}$ to $90 \% \mathrm{RH}$ (Table S5). Importantly, the energy and power densities of the STB increase with increasing air humidity, and the $\mathrm{CaCl}_{2} @ \mathrm{GA}$-based STB achieves record high energy density of $1580 \mathrm{Wh} \cdot \mathrm{kg}^{-1}$ and high power density of $815 \mathrm{~W} \cdot \mathrm{kg}^{-1}$ (Figure $4 \mathrm{f}$ ).

In summary, we reported a high-performance graphene aerogel (GA)-based composite sorbent for sorption thermal battery by confining calcium chloride $\left(\mathrm{CaCl}_{2}\right)$ inside a GA matrix $\left(\mathrm{CaCl}_{2} @ \mathrm{GA}\right)$. The 3D network porous structure and high porosity of the GA matrix endows the $\mathrm{CaCl}_{2} @ \mathrm{GA}$ composite sorbents with large salt loading (96 wt \%), high water uptake $\left(2.89 \mathrm{~g} \cdot \mathrm{g}^{-1}\right)$, excellent thermal stability, and fast sorption kinetics. We further demonstrated a lab-scale $\mathrm{CaCl}_{2} @$ GA-based sorption thermal battery (STB) for efficient thermal energy harvesting and storage, exhibiting record high energy density of $1580 \mathrm{Wh} \cdot \mathrm{kg}^{-1}$ and high power density of $815 \mathrm{~W}$. $\mathrm{kg}^{-1}$. The STB can simultaneously realize temperature and humidity control of indoor air for space heating with high energy density and superior energy efficiency. Our work offers a low-carbon route to realize high-energy/power-density thermal energy harvesting and storage for space heating.

\section{ASSOCIATED CONTENT}

\section{SI Supporting Information}

The Supporting Information is available free of charge at https://pubs.acs.org/doi/10.1021/acsenergylett.1c00284.

Experimental details, computational details, material characterizations, water sorption isobars, and results of partial experiments (PDF)

\section{AUTHOR INFORMATION}

\section{Corresponding Authors}

Tingxian Li - Research Center of Solar Power \& Refrigeration, School of Mechanical Engineering, Shanghai Jiao Tong University, Shanghai 200240, China; (1) orcid.org/00000003-4618-8144; Email: Litx@situ.edu.cn

Ruzhu Wang - Research Center of Solar Power \& Refrigeration, School of Mechanical Engineering, Shanghai Jiao Tong University, Shanghai 200240, China; 이이.org/0000-0003-3586-5728; Email: Rzwang@ sjtu.edu.cn

\section{Authors}

Taisen Yan - Research Center of Solar Power \& Refrigeration, School of Mechanical Engineering, Shanghai Jiao Tong University, Shanghai 200240, China; (1) orcid.org/00000001-6623-0974

Jiaxing Xu - Research Center of Solar Power \& Refrigeration, School of Mechanical Engineering, Shanghai Jiao Tong University, Shanghai 200240, China; (1) orcid.org/00000002-8913-9783

Jingwei Chao - Research Center of Solar Power \& Refrigeration, School of Mechanical Engineering, Shanghai Jiao Tong University, Shanghai 200240, China

Yuri I. Aristov - Boreskov Institute of Catalysis, Russian Academy of Sciences, Novosibirsk 630090, Russia

Larisa G. Gordeeva - Boreskov Institute of Catalysis, Russian Academy of Sciences, Novosibirsk 630090, Russia 
Pradip Dutta - Department of Mechanical Engineering Indian Institute of Science, Bangalore 560012, India

S. Srinivasa Murthy - Interdisciplinary Centre for Energy Research, Indian Institute of Science, Bangalore 560012, India

Complete contact information is available at:

https://pubs.acs.org/10.1021/acsenergylett.1c00284

\section{Author Contributions}

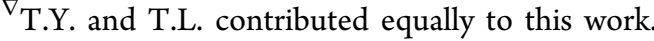

\section{Notes}

The authors declare no competing financial interest.

\section{ACKNOWLEDGMENTS}

This work is supported by the joint international project of BRICS Countries under the National Key R\&D Program of China (Grant 2018YFE0100300), the Russian Foundation for Basic Researches (Grant 18-58-80047), and the Department of Science \& Technology of India (Grant BRICS2017-422).

\section{REFERENCES}

(1) Gur, I.; Sawyer, K.; Prasher, R. Searching for a Better Thermal Battery. Science 2012, 335, 1454.

(2) Zhang, Y. N.; Wang, R. Z. Sorption Thermal Energy Storage: Concept, Process, Applications and Perspectives. Energy Storage Mater. 2020, 27, 352-369.

(3) De Lange, M. F.; Verouden, K. J.; Vlugt, T. J.; Gascon, J.; Kapteijn, F. Adsorption-Driven Heat Pumps: the Potential of MetalOrganic Frameworks. Chem. Rev. 2015, 115, 12205-12250.

(4) Liu, X.; Wang, X.; Kapteijn, F. Water and Metal-Organic Frameworks: from Interaction toward Utilization. Chem. Rev. 2020, 120 (16), 8303-8377.

(5) Xu, J. X.; Chao, J. W.; Li, T. X.; Yan, T. S.; Wu, S.; Wu, M. Q.; Zhao, B. C.; Wang, R. Z. Near-Zero-Energy Smart Battery Thermal Management Enabled by Sorption Energy Harvesting from Air. ACS Cent. Sci. 2020, 6, 1542-1554.

(6) Wang, C. X.; Hua, L. J.; Yan, H. Z.; Li, B. J.; Tu, Y. D.; Wang, R. Z. A Thermal Management Strategy for Electronic Devices Based on Moisture Sorption-Desorption Processes. Joule 2020, 4, 435-447.

(7) Li, T. X.; Wang, R. Z.; Yan, T. Solid-Gas Thermochemical Sorption Thermal Battery for Solar Cooling and Heating Energy Storage and Heat Transformer. Energy 2015, 84, 745-758.

(8) Narayanan, S.; Li, X.; Yang, S.; Kim, H.; Umans, A.; Mckay, I. S.; Wang, E. N. Thermal Battery for Portable Climate Control. Appl. Energy 2015, 149, 104-116.

(9) Li, T. X.; Wang, R. Z.; Li, H. Progress in the Development of Solid-Gas Sorption Refrigeration Thermodynamic Cycle Driven by Low-Grade Thermal Energy. Prog. Energy Combust. Sci. 2014, 40, 158.

(10) Kim, H.; Yang, S.; Rao, S. R.; Narayanan, S.; Kapustin, E. A.; Furukawa, H.; Umans, A. S.; Yaghi, O. M.; Wang, E. N. Water Harvesting from Air with Metal-Organic Frameworks Powered by Natural Sunlight. Science 2017, 356, 430-434.

(11) Zhang, Y. N.; Dong, H. H.; Wang, R. Z.; Feng, P. H. Air Humidity Assisted Sorption Thermal Battery Governed by Reaction Wave Model. Energy Storage Mater. 2020, 27, 9-16.

(12) Li, T. X.; Xu, J. X.; Yan, T.; Wang, R. Z. Development of Sorption Thermal Battery for Low-Grade Waste Heat Recovery and Combined Cold and Heat Energy Storage. Energy 2016, 107, 347359.

(13) James, S. L. Metal-Organic Frameworks. Chem. Soc. Rev. 2003, 32, 276-288.

(14) Férey, G.; Mellot-Draznieks, C.; Serre, C.; Millange, F.; Dutour, J. A Chromium Terephthalate-Based Solid with Unusually Large Pore Volumes and Surface Area. Science 2005, 309, 2040-2042.
(15) Furukawa, H.; Gandara, F.; Zhang, Y. B.; Jiang, J.; Queen, W. L.; Hudson, M. R.; Yaghi, O. M. Water Adsorption in Porous MetalOrganic Frameworks and Related Materials. J. Am. Chem. Soc. 2014, 136, 4369-4381.

(16) Wang, S.; Lee, J. S.; Wahiduzzaman, M.; Park, J.; Muschi, M.; Martineau-Corcos, C.; Tissot, A.; Cho, K. H.; Marrot, J.; Shepard, W.; Maurin, G.; Chang, J.-S.; Serre, C. A Robust Large-Pore Zirconium Carboxylate Metal-Organic Framework for Energy-Efficient WaterSorption-Driven Refrigeration. Nat. Energy 2018, 3, 985-993.

(17) Rieth, A. J.; Wright, A. M.; Skorupskii, G.; Mancuso, J. L.; Hendon, C. H.; Dinca, M. Record-Setting Sorbents for Reversible Water Uptake by Systematic Anion Exchanges in Metal-Organic Frameworks. J. Am. Chem. Soc. 2019, 141, 13858-13866.

(18) Rieth, A. J.; Wright, A. M.; Rao, S.; Kim, H.; Lapotin, A. D.; Wang, E. N.; Dinca, M. Tunable Metal-Organic Frameworks enable High Efficiency Cascaded Adsorption Heat Pumps. J. Am. Chem. Soc. 2018, 140, 17591-17596.

(19) Towsif Abtab, S. M.; Alezi, D.; Bhatt, P. M.; Shkurenko, A.; Belmabkhout, Y.; Aggarwal, H.; Weseliński, Ł. J.; Alsadun, N.; Samin, U.; Hedhili, M. N.; Eddaoudi, M. Reticular Chemistry in Action: a hydrolytically Stable MOF Capturing Twice Its Weight in Adsorbed Water. Chem. 2018, 4, 94-105.

(20) Fathieh, F.; Kalmutzki, M. J.; Kapustin, E. A.; Waller, P. J.; Yang, J.; Yaghi, O. M. Practical Water Production from Desert Air. Sci. $A d v$. 2018, 4, No. eaat3198.

(21) Cho, K. H.; Borges, D. D.; Lee, U. H.; Lee, J. S.; Yoon, J. W.; Cho, S. J.; Park, J.; Lombardo, W.; Moon, D.; Sapienza, A.; Maurin, G.; Chang, J. S. Rational Design of a Robust Aluminum MetalOrganic Framework for Multi-Purpose Water-Sorption-Driven Heat Allocations. Nat. Commun. 2020, 11, 5112.

(22) Hanikel, N.; Prévot, M. S.; Yaghi, O. M. MOF Water Harvesters. Nat. Nanotechnol. 2020, 15, 348-355.

(23) Canivet, J.; Fateeva, A.; Guo, Y.; Coasne, B.; Farrusseng, D. Water Adsorption in MOFs: Fundamentals and Applications. Chem. Soc. Rev. 2014, 43, 5594-5617.

(24) Xu, J. X.; Li, T. X.; Chao, J. W.; Wu, S.; Yan, T. S.; Li, W. C.; Cao, B. Y.; Wang, R. Z. Efficient Solar-Driven Water Harvesting from Arid Air with Metal-Organic Frameworks Modified by Hygroscopic Salt. Angew. Chem., Int. Ed. 2020, 59, 5202.

(25) Yan, T.; Wang, R. Z.; Li, T. X.; Wang, L. W.; Fred, I. T. A Review of Promising Candidate Reactions for Chemical Heat Storage. Renewable Sustainable Energy Rev. 2015, 43, 13-31.

(26) Levitskii, E. A.; Aristov, Y. I.; Tokarev, M. M.; Parmon, V. N. "Chemical Heat Accumulators": a New Approach to Accumulating Low Potential Heat. Sol. Energy Mater. Sol. Cells 1996, 44, 219-235.

(27) Gordeeva, L. G.; Aristov, Y. I. Composites "Salt inside Porous Matrix" for Adsorption Heat Transformation: a Current State of the Art and New Trends. Int. J. Low-Carbon Technol. 2012, 7, 288-302.

(28) Permyakova, A.; Wang, S.; Courbon, E.; Nouar, F.; Heymans, N.; D'ans, P.; Barrier, N.; Billemont, P.; De Weireld, G.; Steunou, N.; Frère, M.; Serre, C. Design of Salt-Metal Organic Framework Composites for Seasonal Heat Storage Applications. J. Mater. Chem. A 2017, 5, 12889-12898.

(29) Garzón-Tovar, L.; Pérez-Carvajal, J.; Imaz, I.; Maspoch, D. Composite Salt in Porous Metal-Organic Frameworks for Adsorption Heat Transformation. Adv. Funct. Mater. 2017, 27, 1606424.

(30) Kallenberger, P. A.; Posern, K.; Linnow, K.; Brieler, F. J.; Steiger, M.; Fröba, M. Alginate-Derived Salt/Polymer Composites for Thermochemical Heat Storage. Adv. Sustainable Systems 2018, 2, 1700160 .

(31) Yang, K.; Shi, Y.; Wu, M. C.; Wang, W. B.; Jin, Y.; Li, R. Y.; Shahzad, M. W.; Ng, K. C.; Wang, P. Hollow Spherical $\mathrm{SiO}_{2}$ MicroContainer Encapsulation of $\mathrm{LiCl}$ for High-Performance Simultaneous Heat Reallocation and Seawater Desalination. J. Mater. Chem. A 2020 , 8, 1887-1895.

(32) Mao, J. J.; Iocozzia, J.; Huang, J. Y.; Meng, K.; Lai, Y. K.; Lin, Z. Q. Graphene Aerogels for Efficient Energy Storage and Conversion. Energy Environ. Sci. 2018, 11, 772-799. 
(33) Bourikas, K.; Kordulis, C.; Lycourghiotis, A. The role of the liquid-solid interface in the preparation of supported catalysts. Catal. Rev.: Sci. Eng. 2006, 48, 363-444.

(34) Shkatulov, A. I.; Joosten, R.; Fischer, H.; Huinink, H. CoreShell Encapsulation of Salt Hydrates into Mesoporous Silica Shells for Thermochemical Energy Storage. ACS Appl. Energy Mater. 2020, 3, $6860-6869$.

(35) Xu, J. X.; Li, T. X.; Chao, J. W.; Yan, T. S.; Wang, R. Z. High Energy-Density Multi-Form Thermochemical Energy Storage based on Multi-Step Sorption Processes. Energy 2019, 185, 1131-1142.

(36) Aristov, Y. I.; Di Marco, G.; Tokarev, M. M.; Parmon, V. N. Selective Water Sorbents for Multiple Applications: $\mathrm{CaCl}_{2}$ Solution Confined in Micro- and Mesoporous Silica Gels: Pore Size Effect on the "Solidification-Melting" Diagram. React. Kinet. Catal. Lett. 1997, 61, 147-160.

(37) Abdulhalim, R. G.; Bhatt, P. M.; Belmabkhout, Y.; Shkurenko, A.; Adil, K.; Barbour, L. J.; Eddaoudi, M. A Fine-Tuned MetalOrganic Framework for Autonomous Indoor Moisture Control. J. Am. Chem. Soc. 2017, 139, 10715-10722.

(38) Ma, D.; Li, P.; Duan, X. Y.; Li, J. Z.; Shao, P. P.; Lang, Z. L.; Bao, L. X.; Zhang, Y. Y.; Lin, Z. G.; Wang, B. A Hydrolytically Stable V(IV)-Metal-Organic Framework with Photocatalytic Bacteriostatic Activity for Autonomous Indoor Humidity Control. Angew. Chem., Int. Ed. 2020, 59, 3905.

(39) Gordeeva, L. G.; Grekova, A. D.; Aristov, Yu. I. Composites "Li/Ca Halogenides inside Multi-Wall Carbon Nano-Tubes" for Adsorptive Heat Storage. Sol. Energy Mater. Sol. Cells 2016, 155, 176183. 